\title{
Advanced Mathematics for Engineering \& Science - A Fourth Year High School Mathematics Course (Curriculum Exchange)
}

\section{Mr. Joshua M Coriell, Cyber Innovation Center}

Joshua Coriell is a Curriculum Development Specialist at the Cyber Innovation Center's National Integrated Cyber Education Research Center. He graduated from Louisiana Tech University in 2011 with a B.S. in Mathematics. A year later he completed his Master of Arts in Teaching at Louisiana Tech University. He is currently working on a high school mathematics curriculum geared toward students interested in STEM fields.

\section{Dr. Krystal S Corbett, Cyber Innovation Center}

Dr. Krystal Corbett is the Director of Curricula at the Cyber Innovation Center (CIC). She received her B.S. and M.S. in Mechanical Engineering (2008/2010), M.S. in Mathematics (2012), and Ph.D. in Engineering Education (2012) at Louisiana Tech University. Through the CIC, Dr. Corbett manages various educational enterprises. Additionally, she is designing and implementing a three-part middle school elective course, STEM: Explore, Discover, Apply, which fosters excitement in STEM. 


\section{A Fourth Year High School Mathematics Course (Curriculum Exchange)}
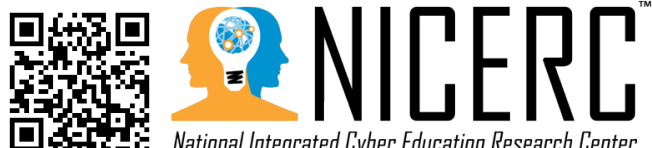

\section{Krystal Corbett, Ph.D.}

Director of Curricula

krystal.corbett@cyberinnovationcenter.org

318-257-2319

\section{Joshua Coriell}

Curriculum Design Specialist

joshua.coriell@cyberinnovationcenter.org

318-257-2319

\section{What is it?}

Advanced Math for Engineering and Science (AMES) is a $12^{\text {th }}$ grade math course covering a wide range of topics, as shown in Figure 1, that prepare students for further study in STEM fields. The overarching theme of the course is to provide a context for the content while driving toward the fundamental mathematics concepts used on a daily basis by engineers and scientists.

\section{How is it structured?}

Each unit in AMES begins with an activity that drives to the fundamentals that are highlighted in that unit's lessons. Throughout the lessons, the students engage in tasks that require researching mathematics history, comparing and contrasting parallel ideas, and communicating mathematics through formal written responses while learning, practicing, and applying the mathematics concepts covered. Concluding each unit is a cumulative project that requires the students to apply what they have learned throughout the unit.

\section{Tell me more about the activites!}

An inexhaustive list of activities in the curriculum is listed in Table 1. The table indicates if the project is an introductory, middle, or closing project; to which unit the project corresponds; and a brief description of the project. Figure 2 shows how the engineering design process (EDP) is used in the curriculum to frame a project where students create and test their own devices to measure radians as accurately as possible.
Figure 1: Topics Covered in AMES

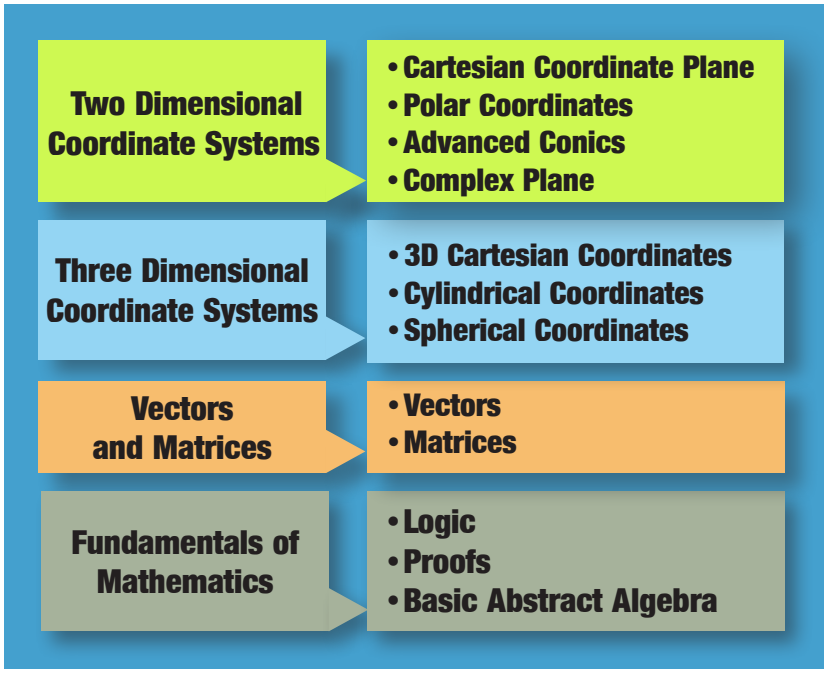

Figure 2: EDP Framing a Radian Project

Table 1: Sample List of Projects

\begin{tabular}{|l|l|l|}
\hline Type of Project & Unit & Brief Description \\
\hline Introduction & Cartesian Coordinates & Locating objects without a system; focuses on specificity \\
\hline Introduction & Vectors & Creating, measuring, and operating on vectors \\
\hline Middle & Cartesian Coordinates & Researching Pythagoras; presenting a Pythagorean Theorem proof \\
\hline Middle & Polar Coordinates & Creating a device that measures one radian \\
\hline Middle & Polar Coordinates & Creating a system of angle measurement \\
\hline Closing & Cartesian Coordinates & Designing and planning the layout of a city \\
\hline Closing & Matrices & Encrypting and decrypting messages with matrices \\
\hline
\end{tabular}

